\title{
Unilateral NMR: A Noninvasive Tool for Monitoring In Situ the Effectiveness of Intervention to Reduce the Capillary Raise of Water in an Ancient Deteriorated Wall Painting
}

\author{
Valeria Di Tullio, ${ }^{1,2}$ Noemi Proietti, ${ }^{1}$ Gennaro Gentile, ${ }^{3}$ \\ Elisabetta Giani, ${ }^{4}$ Domenico Poggi, ${ }^{5}$ and Donatella Capitani ${ }^{1}$ \\ ${ }^{1}$ Laboratorio di Risonanza Magnetica “Annalaura Segre," Istituto di Metodologie Chimiche, CNR, Area della Ricerca di Roma 1, \\ Via Salaria km 29,300, 00015 Monterotondo, Rome, Italy \\ ${ }^{2}$ Dipartimento di Chimica, Centro di Ricerca per le Scienze Applicate alla Protezione dell'Ambiente e dei Beni Culturali, \\ Sapienza Università di Roma, Piazzale Aldo Moro 5, 00185 Rome, Italy \\ ${ }^{3}$ Istituto di Chimica e Tecnologia dei Polimeri, CNR, Via Campi Flegrei 34, 80078 Pozzuoli, Naples, Italy \\ ${ }^{4}$ Istituto Superiore per la Conservazione ed il Restauro, Via di San Michele 22, 00153 Rome, Italy \\ ${ }^{5}$ ArtLab srl, Via Federico Nansen 102, 00154 Rome, Italy
}

Correspondence should be addressed to Noemi Proietti, noemi.proietti@imc.cnr.it

Received 1 June 2011; Accepted 11 October 2011

Academic Editor: Craig J. Eckhardt

Copyright (C) 2012 Valeria Di Tullio et al. This is an open access article distributed under the Creative Commons Attribution License, which permits unrestricted use, distribution, and reproduction in any medium, provided the original work is properly cited.

Portable unilateral NMR was used to quantitatively map in a fully noninvasive way the moisture distribution in an ancient deteriorated wall painting before and after an intervention to reduce the capillary raise of water through the wall. Maps obtained at a depth of $0.5 \mathrm{~cm}$ clearly showed the path of the capillary raise and indicated that, after the intervention, the moisture level was reduced. Maps obtained by measuring the first layers of the wall painting were affected by the critical environmental conditions of the second hypogeous level of St. Clement Basilica, Rome, and by the presence of salts efflorescence and encrustations on the surface of the wall painting. The morphology and the elemental composition of salts investigated by SEM-EDS indicated that efflorescences and encrustations were mostly constituted of gypsum and calcite. The presence of these salts is explained with the presence of high concentration of carbon dioxide and sulphur-rich particles due to pollution which, along with the high-moisture level and the extremely feeble air circulation, cause recarbonation and sulphation processes on the plaster surface.

\section{Introduction}

Water is one of the major causes of decay to masonry materials, and particularly to building masonry belonging to cultural heritage sites [1-3]. The decay of porous stones, the detachment of wall paintings, the salts efflorescence are all phenomena due to the action of water. The moisture rises in the wall to the limit of capillary action or until it evaporates from the wall surface. When salts concentration activity is present in the soil or in the mortar, salts are drawn in solution into the porous network of the wall. Consequently, when salt concentration activities product is greater than the equilibrium constant and/or when the ambient relative humidity becomes lower than the equilibrium relative humidity of the saturated solution of the particular salt phase, salts crystallize causing fretting and crumbling of the wall. The knowledge of the water path and distribution through the wall is mandatory for determining the mechanism by which water triggers and accelerates damage [3]. An accurate diagnosis of the causes and extent of the moisture is a fundamental step in the conservation work. This is particularly true for wall paintings, where a number of special factors must be taken into account, such as the vulnerability of the extremely thin painted surface which is itself the interface between the plaster and the surrounding environment, the difficulty in controlling potential agents of deterioration such as moisture 
and pollution, and the proximity of crowded areas to the wall painting [4]. Furthermore, the preservation planning of wall paintings requires a precise knowledge of the microclimate in proximity of the painted walls [5].

In a recent paper [6] we reported a multitechnique study consisting of microclimate monitoring, infrared thermography (IRT), gravimetric tests, and portable unilateral nuclear magnetic resonance (NMR) which allowed us to map the moisture distribution in a very deteriorated ancient wall painting. In the framework of this study, IRT and gravimetric methods allowed the validation of portable unilateral NMR technique as a new analytical and noninvasive tool for mapping in situ the quantitative distribution of moisture in wall paintings, as well as in any porous material.

Unilateral NMR is a portable technique which allows measurements to be performed in situ and in a fully noninvasive way. The magnetic field is applied to one side of the object, thereby completely preserving the integrity of the object under investigation [7-9].

Unilateral NMR can be successfully applied for mapping and evaluating the moisture distribution particularly where other traditional techniques cannot be applied. This is particularly true in hypogeous environments, where the critical microclimate impairs the use of IRT $[10,11]$. Besides, in ancient precious wall paintings the drilling of solid cores for gravimetric tests is strictly forbidden.

In 2008, we carried out a campaign of NMR measurement for mapping the moisture distribution in a precious deteriorated wall painting located in the second hypogeous level of St. Clement Basilica, Rome (Italy) [12]. That campaign was aimed at evaluating the water damage before planning an intervention to reduce the capillary rise of water from the ground. In this paper, the results of two further campaigns of measurement carried out in 2009 and 2010 after the intervention are reported. Together with NMR measurements, the thermohygrometric parameters were also monitored. Because the surface of the wall painting is affected by efflorescences and encrustations, scanning electron microscopy (SEM) and energy dispersive X-Ray spectroscopy (EDS) were applied for characterizing the morphology and the elemental composition of the salts.

\section{The Study Case}

St. Clement Basilica is a three-tiered complex of buildings: the present Basilica (12th century) located at road level, the Early Christian Basilica (4th century) located at a depth of about $6 \mathrm{~m}$ below the road level, and the oldest building (1th century) located at a depth of $12 \mathrm{~m}$ below the road level.

The presence of a watercourse flowing under the foundation of the Basilica is one of the causes of the rising damp through the walls of the archeological site. Because of the critical microclimate conditions, that is, very high relative humidity and low temperature during the whole year, in the hypogeum, the conservation of artifacts is challenging. The masonry and wall paintings show the characteristic degradation processes induced by a high level of humidity, such as efflorescences, encrustations, and biological colonization.

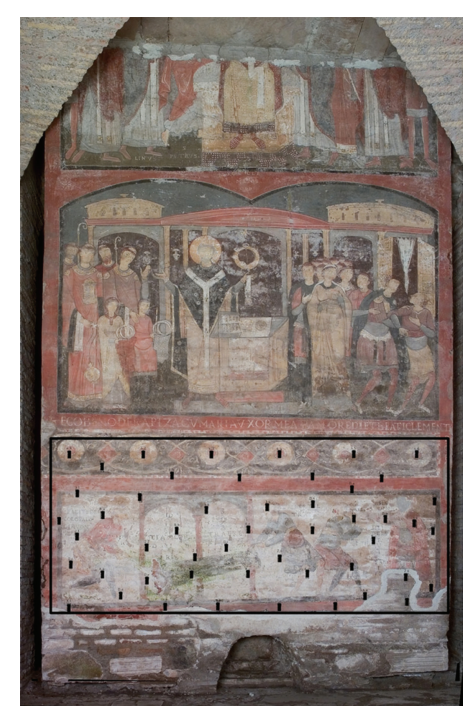

Figure 1: St. Clement at mass and the legend of Sisinnius wall painting. The matrix of points where NMR measurements were carried out is also shown. Marked degradation is observed in the framed area whereas the upper part is in a better state of conservation.

Measurements were carried out in the second hypogeous level where the largest collection of Early Medieval wall paintings is located. Among these, St. Clement at mass and the legend of Sisinnius, a fresco dated back to 1080, see Figure 1, is one of the earliest examples of the passage from Latin to Italian language. The wall painting is rapidly deteriorating due to the capillary raise of water from the ground below. To reduce the rising damp in the masonry, a horizontal cut was carried out through the bricks of the wall just above the floor level, and a hydrophobic mixture of polyester resin and marble powder was introduced in the holes drilled into the wall [13]. The reduction of the rising damp and the stabilization of the level of moisture content were mandatory before performing any restoration of the painted surface.

\section{Experimental}

3.1. Microclimate Monitoring. During the NMR measurements, the thermohygrometric parameters, that is, air temperature $(\mathrm{T})$ and relative humidity $(\mathrm{RH})$, were continuously monitored in the proximity of the wall painting. The temperature on the surface of the wall painting was also monitored. The monitoring was performed with Escort and Gemini Data loggers (range of measurement $0-100 \%$ relative humidity, resolution $\pm 0.5 \%,-30^{\circ} \mathrm{C}$ to $50^{\circ} \mathrm{C}$ temperature, resolution $0.1^{\circ} \mathrm{C}$ ).

3.2. Unilateral NMR. The photo of St. Clement at mass and the legend of Sisinnius is shown in Figure 1, the matrix of points where NMR measurements were carried out is also reported. The degradation markedly affects this area whereas the upper part of the wall painting is in a rather good state of conservation.

In order to map the moisture distribution in the wall painting before and after the intervention to reduce the 
capillary raise of water from the ground, three campaigns of measurement were carried out in situ with a unilateral NMR instrument from Bruker Biospin. The first campaign was carried out on February 2008 before the intervention [12]. The second and third campaigns were carried out four and seven months after the intervention in November 2009 and February 2010, respectively.

Measurements were performed on the first layers of the wall painting and at a depth of about $0.5 \mathrm{~cm}$ in the plaster. In the former case, a $1 \mathrm{~mm}$ probehead operating at $18 \mathrm{MHz}$ was used for measuring at a depth of $0.1 \mathrm{~cm}$ from the surface of the wall painting. In the latter case, a $5 \mathrm{~mm}$ probehead, operating at $16 \mathrm{MHz}$ was used for measuring at a depth between $0.45-0.55 \mathrm{~cm}$, fully disregarding the signal of the surface. In the case of the $1 \mathrm{~mm}$-probehead, the $\pi / 2$ pulse width was $3 \mu \mathrm{s}$, whereas in the case of the $5 \mathrm{~mm}$-probehead it was $10.4 \mu \mathrm{s}$.

Since in an inhomogeneous magnetic field the NMR signal decays very quickly, it must be recovered stroboscopically [14]. Therefore, the integral of the NMR signal is actually the integral of the signal obtained applying a Hahn echo pulse sequence $[15,16]$.

Hahn echo measurements were performed by choosing a matrix of 50 points on the area within the solid framework drawn in Figure 1. Each experimental "point" covered an area of $2 \times 5 \mathrm{~cm}^{2}$, which corresponded to the area of the probehead.

3.3. NMR Data Processing and Evaluation of Moisture Content. Experimental data were processed to obtain a contour plot by applying an algorithm for smoothing sharp variations of the dependent variable values within the $3 \mathrm{D}$ dataset. A Gaussian weight function and a quadratic fit were used to weight the data. A nonlinear function (4th degree polynomial) was then applied to the weighted data for computing each smoothed value [17]. In the obtained map, $x$ and $y$ are the coordinates of the measured area, and $z$ is the integral of the NMR echo signal. The difference in the moisture content is shown with a gradient colour: red indicates the lowest water content, while dark blue indicates the highest water content.

To determine the amount of water in the wall painting, a calibration of the integral of the NMR echo signal was performed using four specimens made by restores. These specimens were prepared according the ancient original recipe to reproduce the same type of mortar used in the wall painting under investigation. The detailed calibration procedure has been reported elsewhere [12]. Briefly, the specimens were dried until they reached a constant weight $P s_{\mathrm{d}}$, then they were fully saturated with water by capillary water absorption up to constant weight $P s_{\mathrm{w}}$. The average values of the weights of the dry $\left(\bar{P} s_{\mathrm{d}}\right)$ and of the water-saturated $\left(\bar{P} s_{\mathrm{w}}\right)$ specimens were used to calculate the imbibition coefficient ic which depends on the type of porous material. This coefficient is calculated from the maximum amount of water adsorbed by the specimen compared to its dry weight:

$$
\text { ic }=\frac{\bar{P} s_{\mathrm{w}}-\bar{P} s_{\mathrm{d}}}{\bar{P} s_{\mathrm{d}}} \cdot 100
$$

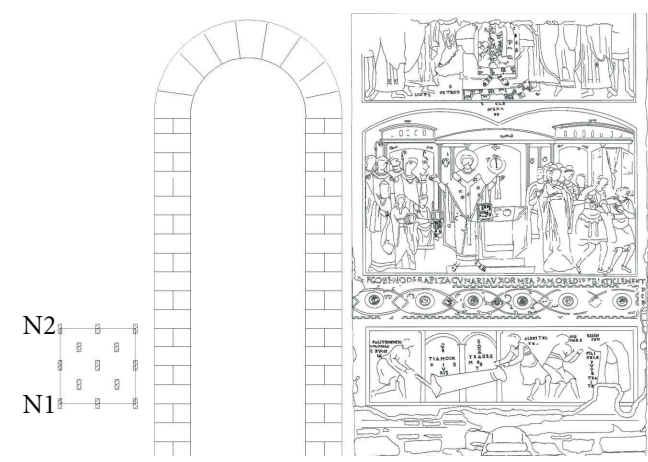

FIGURE 2: The sketch of the wall painting is shown on the right side, and the matrix of points, where both NMR measurements and drilling for gravimetric tests (N1 and N2) were carried out, is shown on the left side.

The correlation between the moisture content obtained by NMR and the imbibition coefficient is given by the following equation:

$$
\mathrm{MC}_{\mathrm{NMR}}^{\mathrm{i}}=\left(A_{\mathrm{p}}^{\mathrm{i}}-A_{\mathrm{pmin}}\right)\left(\frac{\mathrm{ic}}{\bar{A} s_{\mathrm{pw}}-\bar{A} s_{\mathrm{pd}}}\right),
$$

where $A_{\mathrm{p}}^{\mathrm{i}}$ is the integral of the NMR echo signal measured on the area " $i$ " of the matrix selected on the wall painting, $A_{\text {pmin }}$ is the lowest value of the integral measured on the wall painting, and $\bar{A} s_{\mathrm{pd}}$ and $\bar{A} s_{\mathrm{pw}}$ are the average values of the integral of the NMR echo signal measured in the dried and in water-saturated specimens, respectively. According to this calibration procedure, each area of the map obtained corresponds to a precise level of moisture in the wall painting. The calibration of the NMR signal was carried out on data collected both with $1 \mathrm{~mm}$ and $5 \mathrm{~mm}$ probehead.

The maximum error on $\mathrm{MC}_{\mathrm{NMR}}^{\mathrm{i}}$ values was evaluated using the error propagation theory, and it was found to be always less $10 \%$ of the nominal value.

In order to compare results obtained by unilateral NMR and gravimetric tests, an unpainted area located at an elevation of $50 \mathrm{~cm}$ from the floor, at the same height of the wall painting, was chosen. For the sake of clarity, a sketch of this unpainted area is shown on the left side of Figure 2, and a sketch of the wall painting is shown on the right side. On this unpainted area, a matrix of 13 points was chosen where NMR measurements were carried out. From the same matrix, two samples N1 and N2 were collected for the gravimetric tests by scalpel and by hand carbide-tipped chisel, from the surface to $1.5 \mathrm{~cm}$ of depth. The two sampled areas are shown in Figure 2. The powders obtained were placed into glass holders and weighed 30 minutes after collecting them and afterwards dried in an oven at $50^{\circ} \mathrm{C}$ for $24 \mathrm{~h}$. After a coolingoff period, the samples were weighed and moved in a glass holder according to the UNI 11085 protocol [18], dried in an oven at $105^{\circ} \mathrm{C}$, and, after reaching a constant mass, were weighed. The water content was obtained from the difference between the wet and the dry weight with respect to the dry weight. According to the error propagation theory, the uncertainty on data obtained by gravimetric tests was found to be $\pm 1 \%$. 
TABle 1: Moisture content measured in areas N1 and N2 by gravimetric tests and by unilateral NMR carried out at a depth of 0.1 and $0.5 \mathrm{~cm}$.

\begin{tabular}{|c|c|c|c|}
\hline \multirow{2}{*}{ Sample } & \multicolumn{3}{|c|}{ Moisture content (\%) } \\
\hline & Gravimetric test & $\begin{array}{l}\text { Unilateral NMR } \\
\qquad(0.1 \mathrm{~cm})\end{array}$ & $\begin{array}{l}\text { Unilateral NMR } \\
\qquad(0.5 \mathrm{~cm})\end{array}$ \\
\hline N1 & 29 & 31.7 & 24.3 \\
\hline $\mathrm{N} 2$ & 31 & 30.7 & 27.7 \\
\hline
\end{tabular}

The moisture contents measured by NMR at depths of 0.1 and $0.5 \mathrm{~cm}$ and those obtained by gravimetric tests are reported in Table 1. The results of gravimetric tests were found to be in accordance with those obtained by NMR, see Table 1. It is worth noting that the moisture content measured by unilateral NMR at a depth of $0.1 \mathrm{~cm}$ was always found to be higher than that measured at $0.5 \mathrm{~cm}$. This result is in accordance with the results of all previous gravimetric tests performed over the years in unpainted areas of the second level of the Basilica, where the moisture content of the superficial fraction was always found to be higher than that measured at a deeper depth [19]. Besides, the moisture content obtained by gravimetric tests was found to be higher than that obtained by NMR at a depth of $0.5 \mathrm{~cm}$.

3.4. Scanning Electron Microscopy and Energy-Dispersive XRay Spectroscopy. Scanning Electron Microscopy (SEM) and Energy Dispersive X-Ray Spectroscopy (EDS) were performed at Lamest (ICTP-IMCB-CNR, Pozzuoli, Italy) with an FEI Quanta 200 FEG SEM (Eindhoven, The Netherlands) equipped with an Oxford Inca Energy System 250 and an Inca-X-act $\mathrm{LN}_{2}$-free analytical silicon drift detector. Samples collected during the campaign of measurements, carried out in November 2009, were mounted onto SEM stubs by means of carbon adhesive tape and coated with $20 \mathrm{~nm}$ thick gold/palladium layer by means of a modular high-vacuum coating system Leica EM MED 020 (Wien, Austria). SEM micrographs were collected in high-vacuum mode at $20 \mathrm{kV}$ acceleration voltage, with a secondary electron detector. EDS was performed in the range $0-10 \mathrm{keV}$ at $30 \mathrm{kV}$ acceleration voltage. EDS spectra were collected on selected small areas to characterize specific agglomerates, or on large areas to obtain the average composition of each sample. In particular, the average composition was obtained by averaging results obtained from three successive measurements on different areas (about $0.3 \mathrm{~mm}^{2}$ ) of each sample, using the following parameters: acquisition time $200 \mathrm{~s}$, frame time $1.1 \mathrm{~s}$, spot 6 , process time 6 . Elements contained in the support and the coating $(\mathrm{C}, \mathrm{O}, \mathrm{Au}, \mathrm{Pd})$ were discarded from the results of the quantitative analysis.

\section{Results and Discussion}

4.1. Thermohygrometric Parameters Monitoring. The microclimate of the second level of the Basilica is typical of a hypogeous building with very high levels of relative humidity during the whole year.
The monitoring performed in January 2007 and February 2008 clearly showed that the temperature ranged between 13 and $14^{\circ} \mathrm{C}$, and the relative humidity was always higher than $95 \%$ [12].

In October 2009, a scaffolding site consisting of an iron scaffold structure covered with plastic sheets was built in the proximity of the wall painting in order to perform a preliminary investigation before restoration works. In November 2009, when we started performing NMR measurements, the scaffold structure was still there. Contemporary to NMR measurements, the thermohygrometric parameters were monitored inside and outside the scaffold structure. In Figure 3 , the daily trends of temperature and relative humidity outside (Figure 3(a)), and inside (Figure 3(b)) the scaffold structure, are shown. Outside the scaffold structure, the temperature ranged between $17-18^{\circ} \mathrm{C}$, whereas, inside it ranged between 18 and $19^{\circ} \mathrm{C}$. The relative humidity inside was found to be about $10 \%$ lower than outside, as average values of $88 \%$ and $98 \%$ were measured inside and outside the scaffolding site, respectively.

In Figure 3(c), the daily trends of temperature and relative humidity measured in February 2010 in the proximity of the wall painting are shown. Note that at this time the scaffold structure had been removed. The relative humidity ranged between 95 and $100 \%$, and the temperature between 11 and $13^{\circ} \mathrm{C}$. Actually, the microclimate monitoring performed in February 2010 showed a trend very similar to that observed in January 2007, February 2008, and November 2009 outside the scaffolding site.

In Figure 3(d), the trend of the temperature measured on February 2010 at the surface of the wall painting is compared with the dew point. It is worth noting that the temperature at the surface of the wall painting was always at least $1.5^{\circ} \mathrm{C}$ higher than the dew point. Under these circumstances, the occurrence of condensation on the surface of the wall painting can be discarded [5].

4.2. Unilateral NMR. As well known, the deterioration of wall paintings due to the capillary rise of water through the walls is a very widespread problem. In the case of St. Clement at mass and the legend of Sisinnius wall painting damages due to the capillary raise of water are so marked, thus the reduction of dampness and the stabilization of the level of moisture content were mandatory before planning any restoration. Before and after the intervention, the quantitative variation of moisture distribution in the first layers of the wall painting and at a depth of $0.5 \mathrm{~cm}$ was monitored by unilateral NMR.

During all campaigns of measurement, the same matrix of points was investigated, see Figure 1. Data were processed to obtain a contour plot, which is a $2 \mathrm{D}$ representation of a $3 \mathrm{D}$ surface, where $x$ and $y$ were the coordinates of the measured area of the painted wall and $z$ was the integral of the NMR echo signal. As previously reported [20], the integral of the NMR echo signal is proportional to the water content. Contour plots obtained allowed an easy visualization of the detailed distribution of the moisture in the wall painting, see the maps shown in Figure 4. In these maps, the difference in the moisture level is represented as a gradient of colour: dark 


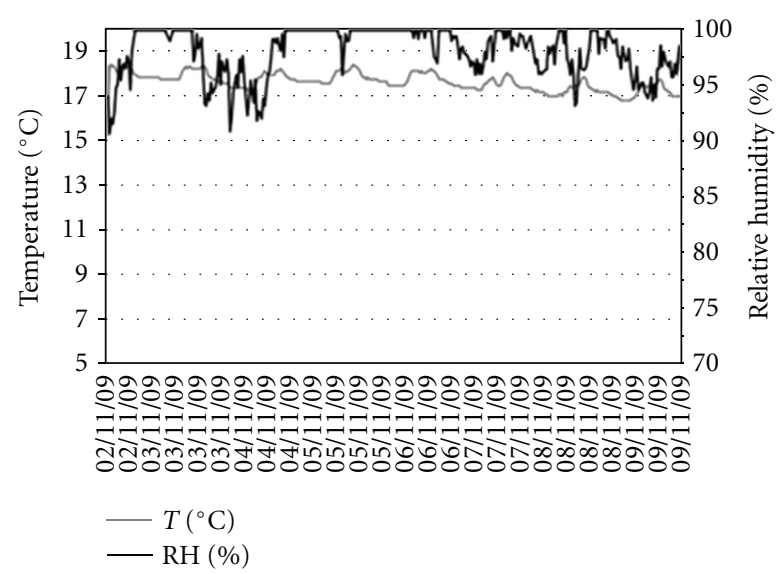

(a)

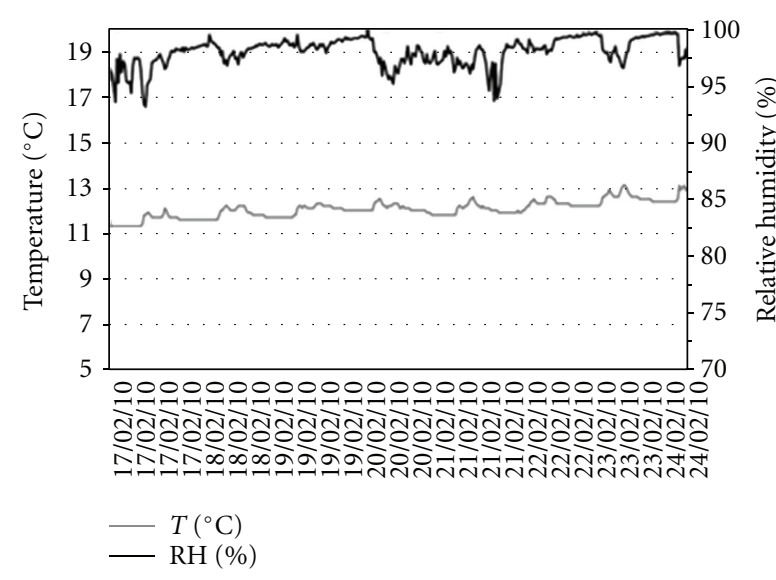

(c)

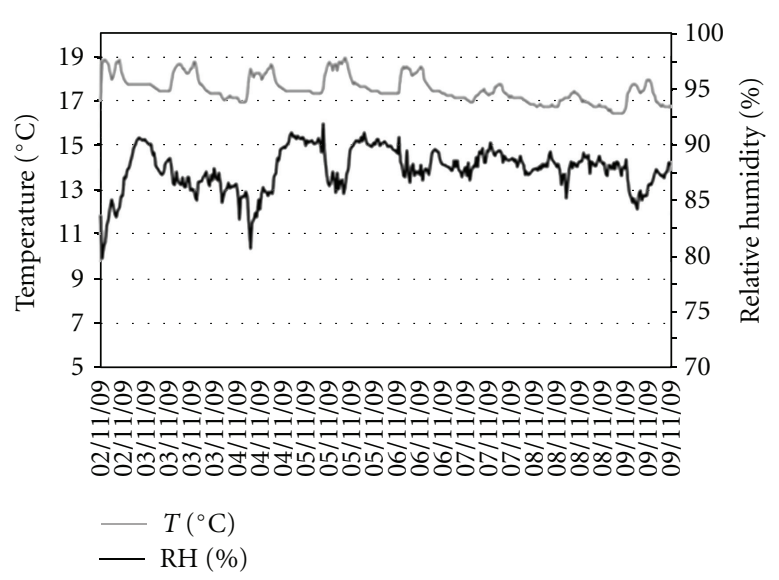

(b)

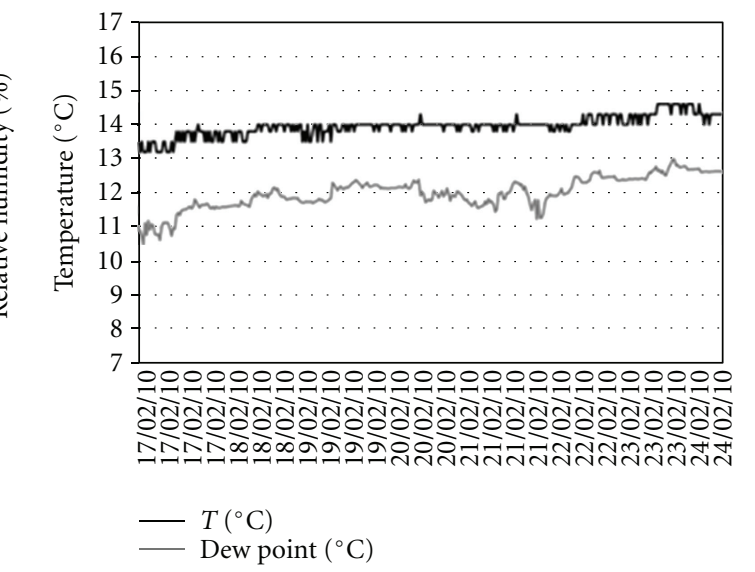

(d)

FIGURE 3: Monitoring of thermohygrometric parameters carried out contemporary to NMR measurements. (a) November 2009, outside the scaffolding site, (b) November 2009, inside the scaffolding site, (c) February 2010, (d) February 2010, comparison between the temperature measured on the wall painting surface and the dew point.

red indicates the lowest moisture content, whereas dark blue indicates the highest moisture content. The maps obtained at a depth of $0.1 \mathrm{~cm}$ are shown on the left side of Figure 4, and the maps obtained at a depth of $0.5 \mathrm{~cm}$ are shown on the right side. In Figures 4(a) and 4(b), maps collected in February 2008, before the intervention to reduce the rising damp, are shown [12]. Maps collected after the intervention in November 2009 and February 2010 are shown in Figures $4(\mathrm{c})$ and $4(\mathrm{~d})$, and in $4(\mathrm{e})$ and $4(\mathrm{f})$, respectively.

All maps obtained at a depth of $0.5 \mathrm{~cm}$ give a clear image of the path of the rising damp originating from the watercourse flowing under the foundation. After the intervention, the maximum water content measured in November 2009 and February 2010 was found to be about 3\% lower than that measured in February 2008 before the intervention. Maps obtained at a depth of $0.1 \mathrm{~cm}$ show that the maximum water content was found to be $12-13 \%$ in February 2008, $10-11 \%$ in November 2009, and $11-12 \%$ in February 2010. These results are in accordance with the results of gravimetric tests performed over the years in unpainted areas of the second level of the Basilica, where the moisture content at the surface of the masonry was found to be always higher than the moisture content measured at a deeper depth [19].

It is worth noting that the moisture maps collected at a depth of $0.1 \mathrm{~cm}$ do not give information about the path of the rising damp. To explain these results it must be taken into account that measurements at a depth of $0.1 \mathrm{~cm}$ regard a slice very close to the wall painting - environment interface, which is also affected by the peculiar microclimate of the hypogeous environment. The influence of microclimate on the quantitative moisture distribution in the first layers of the wall painting was clearly observable in November 2009 when the presence of the scaffolding site caused a net lowering of the relative humidity in the proximity of the wall painting, see Figure 4(c). In fact, the map obtained in November 2009 shows more dry areas than that collected in February 2008 before the intervention, see Figure 4(a), and that collected in February 2010 after the removal of the scaffolding site, see Figure 4(e). Actually, maps collected at a depth of $0.1 \mathrm{~cm}$, before and after the intervention and in absence of the scaffolding site, are very similar to each other and seem to be weakly affected by the intervention. 


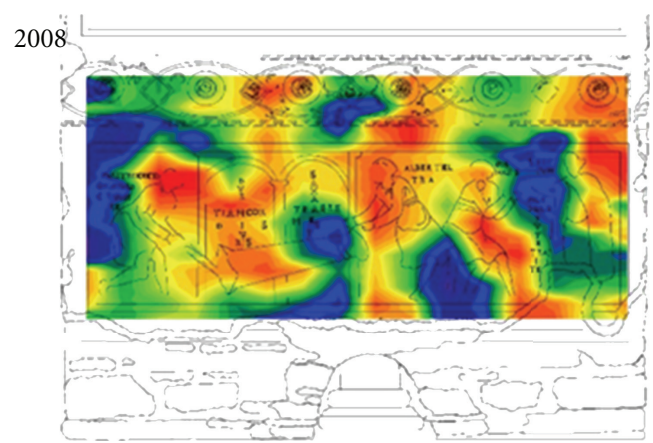

(a)

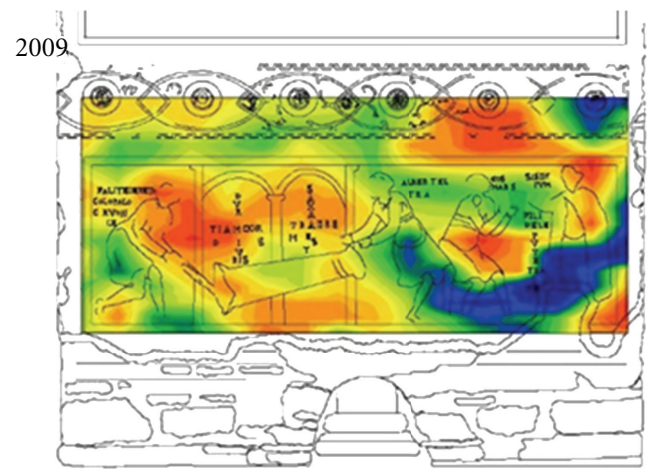

(c)
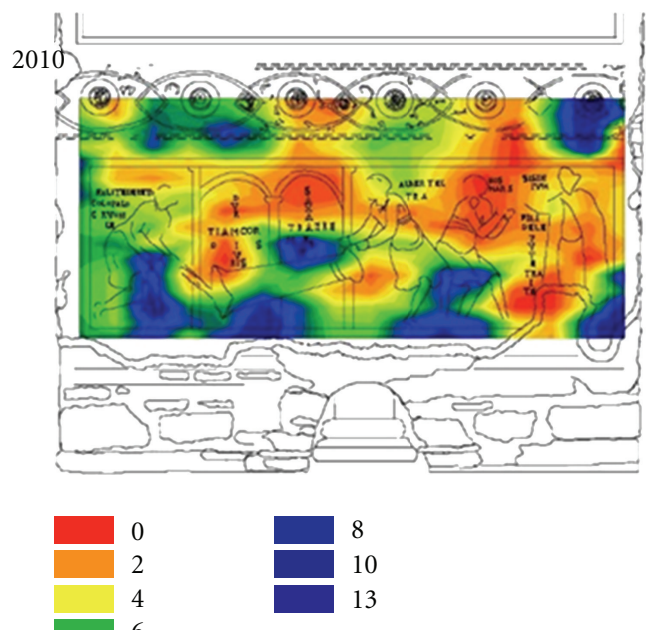

(e)

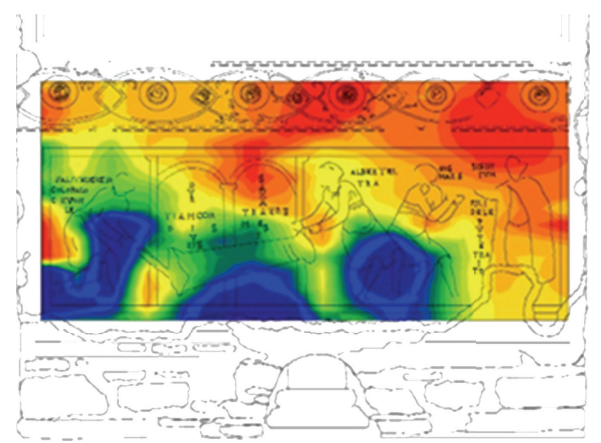

(b)

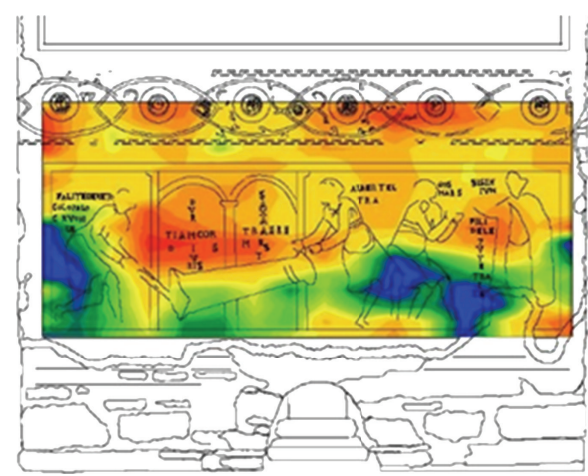

(d)
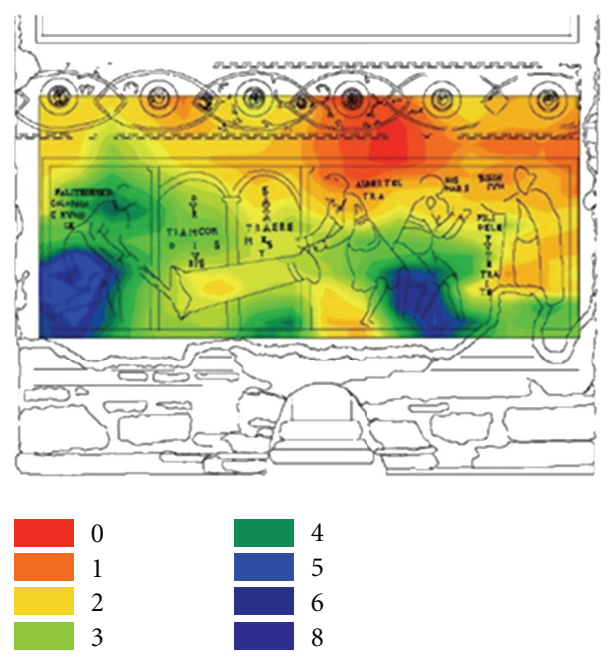

(f)

FIgURE 4: Moisture distribution maps obtained by unilateral NMR at a depth of $0.1 \mathrm{~cm}$ (left) and at a depth of $0.5 \mathrm{~cm}$ (right). Top: maps collected in February 2008 before the intervention to reduce the capillary raise of water through the walls. Middle: maps collected in November 2009 four months after the intervention and in the presence of a scaffolding site in the proximity of the wall painting. Bottom: maps collected in February 2010 seven months after the intervention and after removing the scaffolding site.

The surface of the wall painting shows the degradation processes induced by the high amount of humidity characteristic of a hypogeous environment, and by the rising damp from the ground below, with the presence of biological colonization, efflorescences, and encrustations [21, 22]. In November 2009, the visual inspection of the surface of the wall painting revealed wide areas with thin salts efflorescence such as S1 and S3, areas showing thick salts efflorescence such as S2, and areas with thick encrustation such as S4, see the sketch in Figure 5(a). An area S5 showing thick salts efflorescence was also observed outside the painted surface. The moisture distribution map at $0.1 \mathrm{~cm}$ collected in November 2009 clearly indicates an amount of moisture of about 6\% in S2 and S3 and a very low amount of moisture in S1 and S4, see Figure 5(b).

To investigate the type of encrustations and salts efflorescence affecting the surface of the wall painting, five samples were collected from areas $\mathrm{S} 1-\mathrm{S} 5$. Note that the sampling was 
TABLE 2: Average elemental compositions in atomic \% obtained by EDS analysis of samples S1-S5. Each value was obtained by averaging the elemental compositions measured on three areas of the same sample (standard deviation values in parentheses).

\begin{tabular}{|c|c|c|c|c|c|c|c|c|c|}
\hline \multirow[b]{2}{*}{ Sample } & \multicolumn{9}{|c|}{ Elements (atomic \%) } \\
\hline & $\mathrm{Na}$ & $\mathrm{Mg}$ & $\mathrm{Al}$ & $\mathrm{Si}$ & $S$ & $\mathrm{Cl}$ & $\mathrm{K}$ & $\mathrm{Ca}$ & $\mathrm{Fe}$ \\
\hline S1 & - & $\begin{array}{c}0.34 \\
(0.18)\end{array}$ & $\begin{array}{c}0.46 \\
(0.15)\end{array}$ & $\begin{array}{c}0.72 \\
(0.21)\end{array}$ & $\begin{array}{l}17.23 \\
(0.29)\end{array}$ & $\begin{array}{c}0.60 \\
(0.06)\end{array}$ & - & $\begin{array}{l}80.43 \\
(0.51)\end{array}$ & $\begin{array}{c}0.22 \\
(0.01)\end{array}$ \\
\hline S2 & - & $\begin{array}{c}0.23 \\
(0.11)\end{array}$ & $\begin{array}{c}1.04 \\
(0.22)\end{array}$ & $\begin{array}{c}2.15 \\
(0.32)\end{array}$ & $\begin{array}{l}40.94 \\
(0.85)\end{array}$ & $\begin{array}{c}0.78 \\
(0.02)\end{array}$ & - & $\begin{array}{l}54.42 \\
(0.68)\end{array}$ & $\begin{array}{c}0.45 \\
(0.10)\end{array}$ \\
\hline S3 & - & $\begin{array}{c}0.19 \\
(0.04)\end{array}$ & $\begin{array}{c}0.78 \\
(0.09)\end{array}$ & $\begin{array}{c}1.61 \\
(0.21)\end{array}$ & $\begin{array}{l}35.17 \\
(1.89)\end{array}$ & $\begin{array}{c}0.64 \\
(0.08)\end{array}$ & - & $\begin{array}{l}61.32 \\
(2.20)\end{array}$ & $\begin{array}{c}0.29 \\
(0.10)\end{array}$ \\
\hline S4 & - & $\begin{array}{c}0.74 \\
(0.21)\end{array}$ & $\begin{array}{c}0.57 \\
(0.04)\end{array}$ & $\begin{array}{c}0.77 \\
(0.12)\end{array}$ & - & $\begin{array}{c}0.50 \\
(0.03)\end{array}$ & - & $\begin{array}{l}97.19 \\
(0.37)\end{array}$ & $\begin{array}{c}0.24 \\
(0.02)\end{array}$ \\
\hline S5 & $\begin{array}{c}0.96 \\
(0.22)\end{array}$ & $\begin{array}{c}0.52 \\
(0.17)\end{array}$ & $\begin{array}{c}2.47 \\
(0.45)\end{array}$ & $\begin{array}{c}5.66 \\
(1.35)\end{array}$ & $\begin{array}{c}37.53 \\
(1.33)\end{array}$ & $\begin{array}{c}0.70 \\
(0.05)\end{array}$ & $\begin{array}{c}0.32 \\
(0.08)\end{array}$ & $\begin{array}{l}50.77 \\
(1.29)\end{array}$ & $\begin{array}{c}1.07 \\
(0.31)\end{array}$ \\
\hline
\end{tabular}
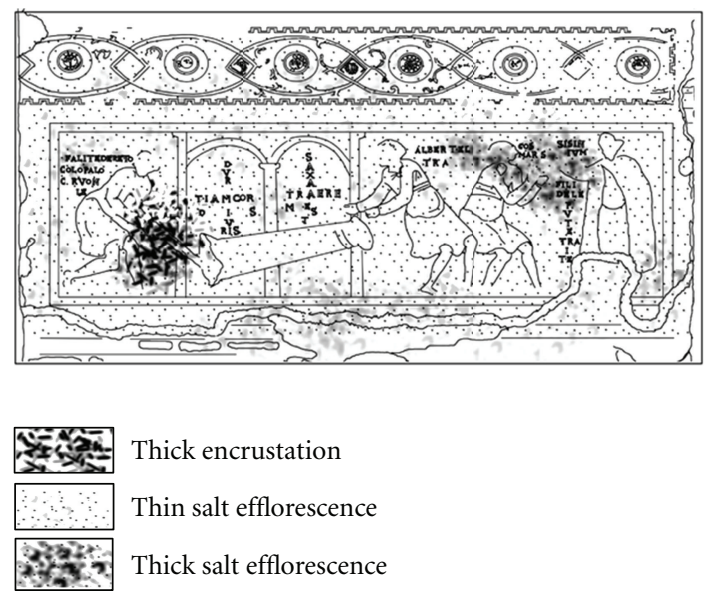

(a)

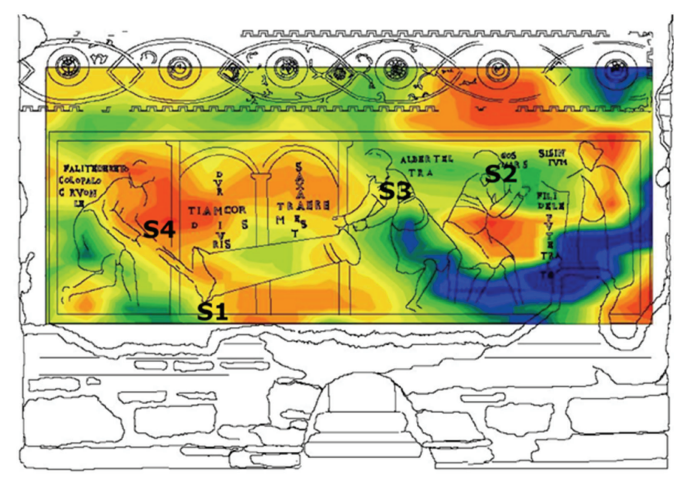

(b)

FIGURE 5: (a) Sketch of the degraded area of the wall painting. (b) Moisture distribution map at a depth of $0.1 \mathrm{~cm}$ obtained in November 2009. Labels evidence few areas sampled for SEM-EDS analysis: S1 and S3 indicate areas showing thin salts efflorescence, S2 indicates an area with thick salts efflorescence, S4 indicates an area with a thick encrustation.

carefully performed at the surface of encrustations and salts efflorescence, avoiding to include parts of the painted fresco.

4.3. SEM-EDS Characterization of Salts Efflorescence and Encrustations. Samples collected from areas S1-S5 were analyzed by SEM-EDS. Average elemental compositions obtained by EDS are reported in Table 2. Samples S1, S2, and S3 were found to be very rich in calcium and sulphur as the amount of both elements accounted for 95$98 \%$ of the total composition. Sample S4 did not contain any sulphur whereas calcium was about $97 \%$ of the total composition. Sample S5 was more heterogeneous than the other samples, with calcium and sulphur accounting for $88 \%$ of the total composition. We selected few SEM images particularly representative of the morphology of the samples, see Figure 6.

An image of an area of sample S2 is shown in Figure 6(a), where intercrossed thick lamellae with rounded borders forming a desert-rose-like aggregate characteristic of gypsum [23], are observed. In this area with a radius of about 10$15 \mu \mathrm{m}$, only calcium and sulphur were detected in a relative atomic ratio of $1: 1$. Based both on the morphology [23] and on the elemental composition, the presence of $\mathrm{CaSO}_{4}$ may be hypothesized.

In Figure 6(b), an image of an area of sample S4 with dendritic aggregates with columnar crystals, is shown. In this, area the EDS analysis revealed a very large amount of calcium, whereas sulphur was not detected. Based both on the characteristic morphology [23] and on the elemental composition, the presence of calcite precipitate may be hypothesized.

Images of areas of samples $\mathrm{S} 1$ and $\mathrm{S} 3$ reported in Figures 6(c) and 6(d), respectively, show a heterogeneous morphology. The EDS analysis of lamellar aggregates in zones 1 clearly revealed the presence of sulphur and calcium in an atomic ratio of about $1: 1$, possibly indicating the presence of $\mathrm{CaSO}_{4}$. The analysis of dendritic aggregates in zones 2 revealed a very large amount of calcium whereas sulphur was not detected, possibly indicating the presence of $\mathrm{CaCO}_{3}$.

All these data suggest that salt efflorescences on the surface of the wall painting are mostly constitued by gypsum and calcite precipitate. By ascribing all the detected sulphur to $\mathrm{CaSO}_{4}$, the weight percentage of gypsum and calcite precipitate was obtained from the atomic ratio between calcium and sulphur, see Table 3. Sample S4 was constituted of calcite precipitate, samples S2 and S5 showed the same 


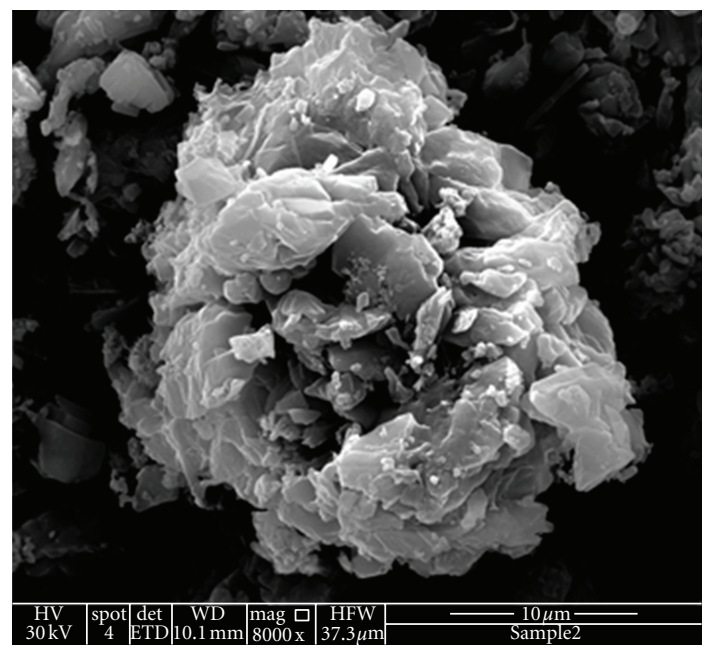

(a)

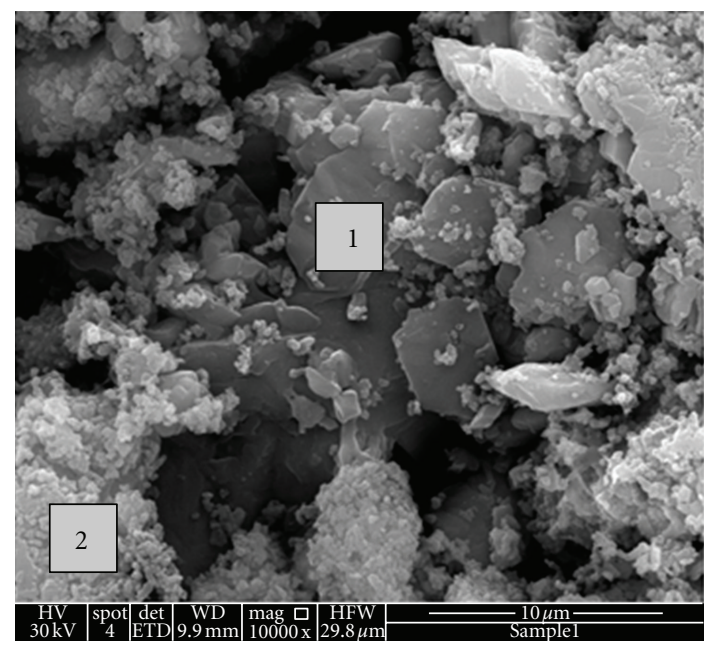

(c)

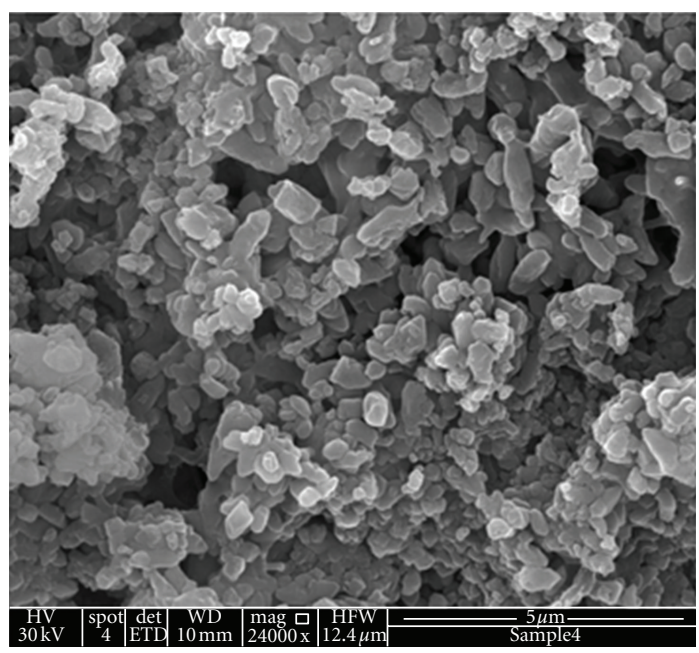

(b)

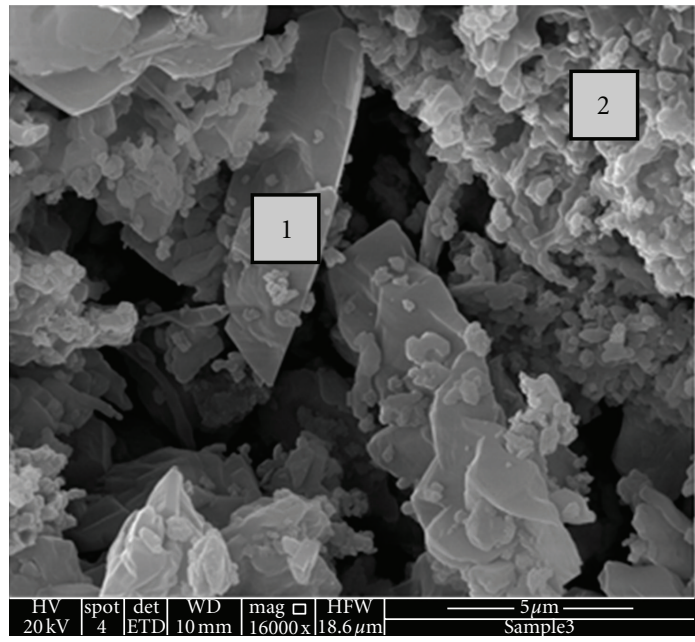

(d)

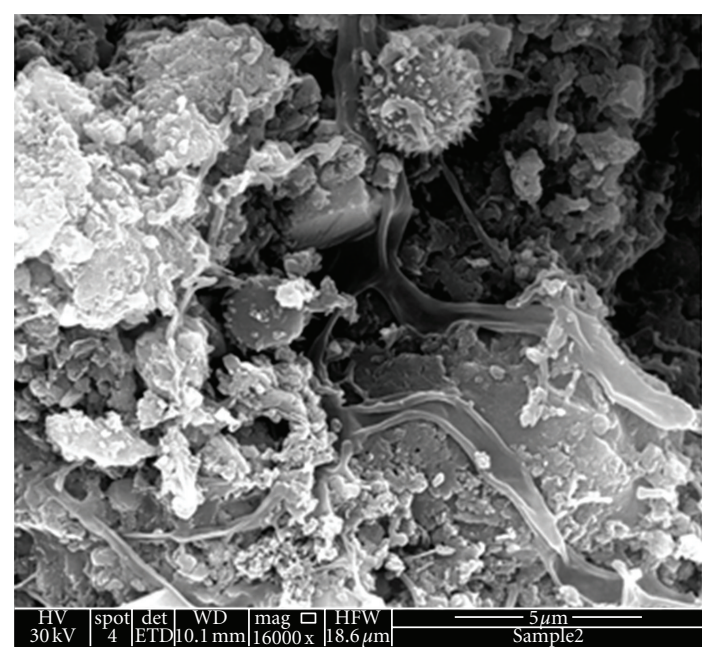

(e)

FIGURE 6: SEM images. (a) Sample S2: gypsum desert-rose like aggregate. (b) Sample S4: dendritic aggregates. (c) Sample S1: zone 1, lamellae, zone 2, dendritic aggregates. (d) Sample S3: zone 1, lamellae, zone 2, dendritic aggregates. (e) Sample S2, biological colonization. 
TABLE 3: Relative amount of calcium carbonate and calcium sulphate, expressed in atomic ratio and weight percentage.

\begin{tabular}{lccc}
\hline Sample & $\begin{array}{c}\text { Atomic ratio } \\
\mathrm{CaSO}_{4} / \mathrm{CaCO}_{3}\end{array}$ & $\begin{array}{c}\mathrm{CaSO}_{4} \text { relative } \\
\text { amount }(\mathrm{wt} \%)\end{array}$ & $\begin{array}{c}\mathrm{CaCO}_{3} \text { relative } \\
\text { amount }(\mathrm{wt} \%)\end{array}$ \\
\hline S1 & 0.27 & 27.0 & 73.0 \\
S2 & 3.12 & 80.9 & 19.1 \\
S3 & 1.35 & 64.7 & 35.3 \\
S4 & 0.00 & 0.0 & 100.0 \\
S5 & 2.86 & 79.4 & 20.6 \\
\hline
\end{tabular}

average composition with about $20 \mathrm{wt} \%$ of calcite precipitate and $80 \mathrm{wt} \%$ of gypsum. Sample S1 was rich in calcite precipitate $(73 \mathrm{wt} \%)$, whereas sample $\mathrm{S} 3$ was rich in gypsum (65 wt\%).

These results are in accordance with the results obtained in previous studies [24] which had evidenced the presence of high concentration of calcium and sulphur ions on the surface of the unpainted masonry of the second hypogeous level of the Basilica. The high concentration of these ions had been related to the high concentration of gaseous $\left(\mathrm{CO}_{2}\right)$ and particles pollutants rich in sulphur measured in the hypogeous level. In fact, the extremely feeble air circulation in that level is not able to dilute the pollutants concentration which remains always high causing damages to the masonry surface $[24,25]$. The high concentration of sulphur-rich particles and the high carbon dioxide concentration along with the action of moisture cause, respectively, sulphation and recarbonation processes on the plaster surface [26].

The presence of biological colonization is clearly observable in Figure 6(e), where the image of an area with spores and plants is shown.

\section{Conclusion}

Unilateral NMR was used to quantitatively map in situ, in a fully non-invasive way, the moisture distribution in a precious and ancient deteriorated wall painting, before and after an intervention to reduce the capillary raise of water through the walls. Because of the critical environmental conditions of the second hypogeous level of St. Clement Basilica (Rome), where the wall painting is located, contemporary to NMR measurements, the monitoring of the thermohygrometric parameters was also carried out.

NMR measurements performed at a depth of $0.5 \mathrm{~cm}$ allowed us to monitor the path of the capillary raise of water through the walls before and after the intervention. The moisture distribution maps obtained four and seven months after the intervention clearly showed a lowering of the path of the rising damp and a net reduction of wet areas.

The monitoring of the thermohygrometric parameters allowed us to better understand the NMR moisture maps obtained at a depth of $0.1 \mathrm{~cm}$. In fact, at this depth, the moisture content was found to be affected by the environmental conditions. By comparing the NMR moisture maps at a depth of $0.1 \mathrm{~cm}$, it was found that the map with the lowest moisture content and the highest number of dry areas was obtained after the intervention in presence of a scaffolding site, when the relative humidity measured inside this structure was, on average, about $10 \%$ lower than outside the structure. After removing the scaffolding site, the moisture distribution at a depth of $0.1 \mathrm{~cm}$ was found to be similar to that obtained before the intervention.

Because of the thermohygrometric conditions of the hypogeum and the capillary raise of water from the ground below, the surface of the wall painting shows a marked degradation, with the presence of biological colonization, efflorescence, and encrustations. To investigate the composition of the salts, an SEM-EDS analysis of a few selected areas was carried out. The analysis revealed that efflorescences and encrustations were mostly constituted of gypsum and calcite precipitate. These results were in accordance with a previous study which had evidenced the presence of a high concentration of calcium and sulphur ions on the surface of the masonry of the second hypogeous level of the Basilica. The high concentration of these ions had been related to the high concentration of gaseous and particles pollutants that, because of the extremely feeble air circulation, remains always high, causing damages to the masonry surface. The high concentration of sulphur-rich particles and the high carbon dioxide concentration along with the action of moisture, cause, respectively, sulphation, and recarbonation processes on the plaster surface. It is worth noting that in the particular environmental conditions of the hypogeum, low temperature, and high relative humidity, the high carbon dioxide concentration makes the moisture on the surface of the wall painting more acidic. As a consequence, the calcium carbonate of the plaster is transformed into calcium bicarbonate that is about one hundred times more soluble than calcium carbonate. Under these circumstances, even a slight increase of the temperature due to the opening of the archaeological site to visitors causes an evaporation of carbon dioxide and calcium bicarbonate precipitates as calcium carbonate on the surface of the wall painting (recarbonation). The damage caused by the recarbonation process is twofold: the formation of salts efflorescence on the surface of the wall painting, and, at the same time, the consumption of the plaster.

To summarize, the quantitative moisture distribution obtained by NMR was of help in planning the intervention project to reduce the capillary raise of water. The monitoring of the evolution of the water distribution in the wall painting after the intervention gave important information on the effectiveness of the intervention and on the modification occurring in the path of the rising damp after the intervention. Besides the NMR investigation at the surface of the wall painting clearly showed that the degradation affecting the surface also depends on the microclimate of the hypogeum. In fact, the presence of a scaffolding site, often used during restoration works, is capable of affecting the thermohygrometric parameters measured at the surface of the wall painting.

\section{References}

[1] V. G. G. Amoroso and V. Fassina, Stone Decay and Conservation, Elsevier, Lausanne, Switzerland, 1983. 
[2] L. R. P. J. van Hees, I. L. Binda, I. Papayianni, and E. Toumbakari, "Recommendations of RILEM TC 167-COM: characterization of old mortars characterisation and damage analysis of old mortars," Materials and Structures, vol. 37, pp. 648-664, 2004.

[3] A. Sansonetti, E. Rosina, and N. Ludwig, "Moisture damage," Materials Evaluation, vol. 69, no. 1, pp. 41-46, 2011.

[4] M. Matteini, "An assessment of florentine methods of wall painting conservation based on the use of mineral treatments," in Conservation of Wall Paintings Proceedings of a Symposium Organized by the Courtauld Institute of Art and the Getty Conservation Institute, London, July 13-16, S. Cather, Ed., pp. 137-147, 1987.

[5] D. Camuffo, Microclimate for Cultural Heritage, Elsevier Science, Amsterdam, The Netherlands, 1998.

[6] D. Capitani, N. Proietti, M. Gobbino et al., "An integrated study for mapping the moisture distribution in an ancient damaged wall painting," Analytical and Bioanalytical Chemistry, vol. 395, no. 7, pp. 2245-2253, 2009.

[7] S. Sharma, F. Casanova, W. Wache, A. Segre, and B. Blümich, "Analysis of historical porous building materials by the NMRMOUSE," Magnetic Resonance Imaging, vol. 21, no. 3-4, pp. 249-255, 2003.

[8] B. Blümich, J. Perlo, and F. Casanova, "Mobile single-sided NMR," Progress in Nuclear Magnetic Resonance Spectroscopy, vol. 52, no. 4, pp. 197-269, 2008.

[9] R. Olmi, S. Priori, D. Capitani et al., "Innovative techniques for sub-surface investigations," Materials Evaluation, vol. 69, no. 1, pp. 89-96, 2011.

[10] E. Rosina and N. Ludwig, "Optimal thermographic procedures for moisture analysis in buildings materials," in Proceedings of the Diagnostic Imaging Technologies and Industrial Applications Conference, vol. 3827 of Proceedings of SPIE, pp. 22-33, International Society for Optical Engineering, 1999.

[11] L. Ludwig and E. Rosina, "Active and passive thermography to detect moisture in building materials," in Proceedings of the 5th International Workshop on Advanced Infrared Technology and Applications (AITA '99), pp. 166-175, 1999.

[12] V. Di Tullio, N. Proietti, M. Gobbino et al., "Non-destructive mapping of dampness and salts in degraded wall paintings in hypogeous buildings: The case of St. Clement at mass fresco in St. Clement Basilica, Rome," Analytical and Bioanalytical Chemistry, vol. 396, no. 5, pp. 1885-1896, 2010.

[13] G. Massari and I. Massari, Damp Building Old and New, ICCROM, Rome, Italy, 1993.

[14] B. Blümich, S. Anferova, K. Kremer, S. Sharma, V. Herrmann, and A. Segre, "Unilateral nuclear magnetic resonance for quality control: the NMR-mouse," Spectroscopy, vol. 18, no. 2, pp. 18-29, 2003.

[15] E. L. Hahn, "Spin echoes," Physical Review, vol. 80, pp. 580594, 1950.

[16] T. C. Farrar and E. D. Becker, Pulse and Fourier Transform NMR, Academic Press, New York, NY, USA, 1971.

[17] S. Di Zenzo, "A note on the gradient of a multi-image," Computer Vision, Graphics and Image Processing, vol. 33, no. 1, pp. 116-125, 1986.

[18] Water Absorption by Total Immersion, Italian Recommendation NORMAL 7/81, ICR, Rome, Italy, 1981.

[19] M. Coladonato, E. Giani, A. Giovagnoli, and R. Rinaldi, "Environmental study for the safety of frescos in hypogeous site: the relationship between the water quantity and the solubile salts into the masonry," in Proceedings of the 6th International
Conference on Non-destructive Testing. Microanalytical Methods and Environmental Evaluation for Study and Conservation of Works of Art, Rome, Italy, 1996.

[20] N. Proietti, D. Capitani, S. Cozzolino et al., "In situ and frontal polymerization for the consolidation of porous stones: a unilateral NMR and magnetic resonance imaging study," Journal of Physical Chemistry B, vol. 110, no. 47, pp. 2371923728, 2006.

[21] A. Arnold and A. Kueng, "Crystallization and habits of salt efflorescence on walls I-methods of investigation and habits," in Proceedings of the 5th International Congress on Deterioration and Conservation of Stone, Losanne, Switzerland, 1985.

[22] A. Arnold and K. Zehnder, "Crystallization and habits of salt efflorescence on walls II condition of crystallization," in Proceedings of the 5th International Congress on Deterioration and Conservation of Stone, Losanne, Switzerland, 1985.

[23] A. Begonha, "Mineralogical study of the deterioration of granite stones of two Portuguese churches and characterization of the salt solutions in the porous network by the presence of diatoms," Materials Characterization, vol. 60, no. 7, pp. 621635, 2009.

[24] E. Giani, A. Giovagnoli, and A. Pietrini, "Roma Basilica di San Clemente-Metodologie di Indagine per lo studio ambientale," Conservazione e Restauro, pp. 74-78, 2004.

[25] G. Accardo, G Gerardi, E. Giani, R. Rinaldi, and S. Scardigli, "Physical methodologies to set up more idoneous environmental conditions for the safety of frescoes: the case of S. Clemente in Rome," in Proceedings of the 5th International Conference on Non-Destructive Testing, Microanalytical Methods and Environmental Evaluation for Study and Conservation of Works of Art, Budapest, Hungary, 1996.

[26] V. Fassina, "Basic Chemical Mechanisms outdoors," in Basic Environmental Mechanism Affecting Cultural Heritage, Understanding Deterioration Mechanism for Conservation Purpose, D. Camuffo, V. Fassina, and J. Havermans, Eds., chapter 7, pp. 8687, Nardini Editore, Firenze, Italy, 2010. 


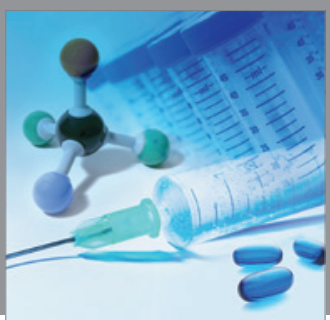

International Journal of

Medicinal Chemistry

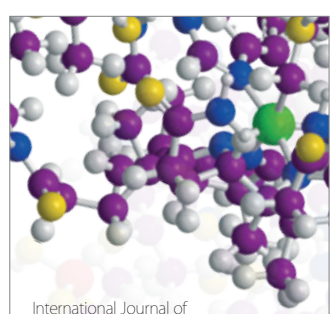

Carbohydrate Chemistry

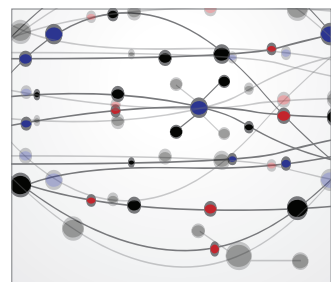

The Scientific World Journal
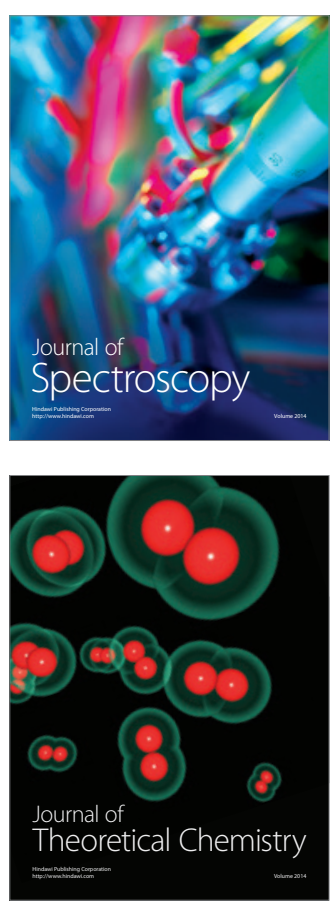
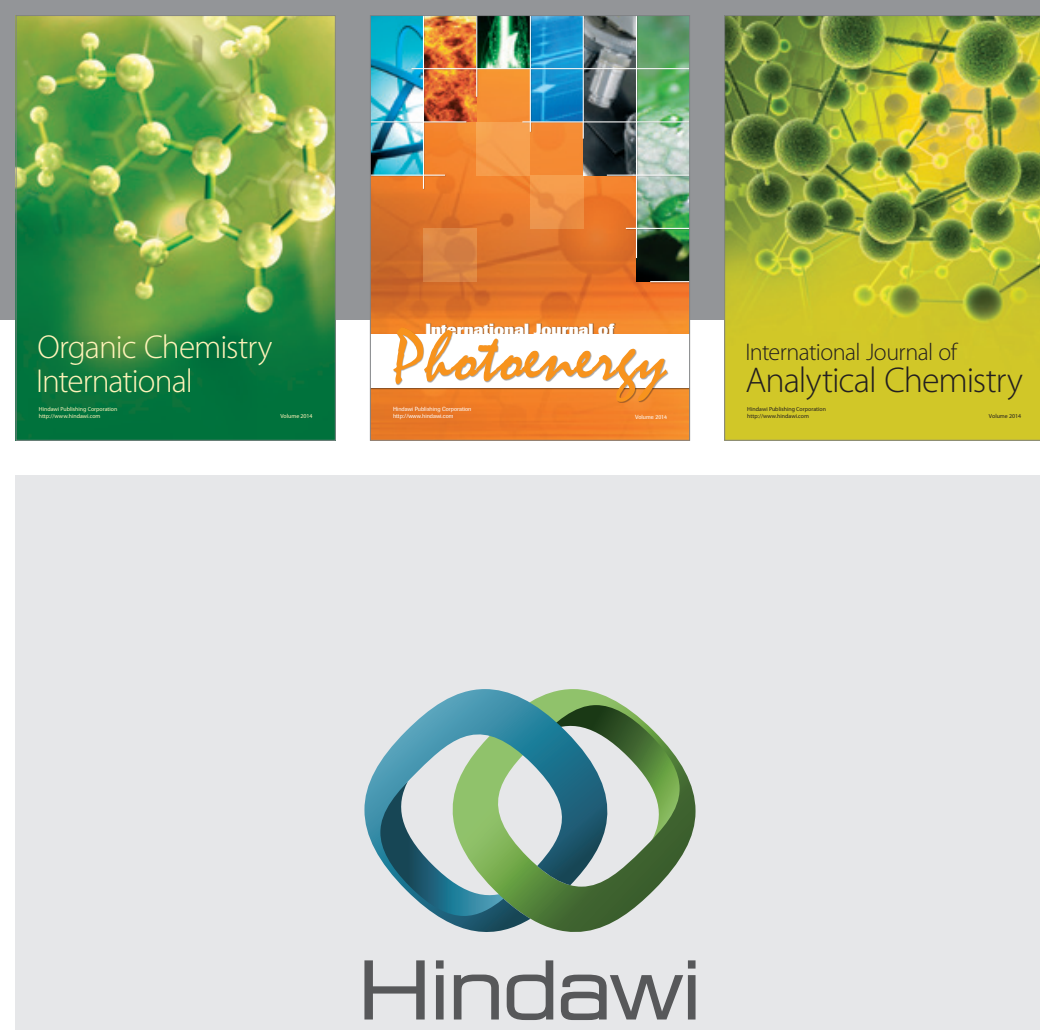

Submit your manuscripts at

http://www.hindawi.com
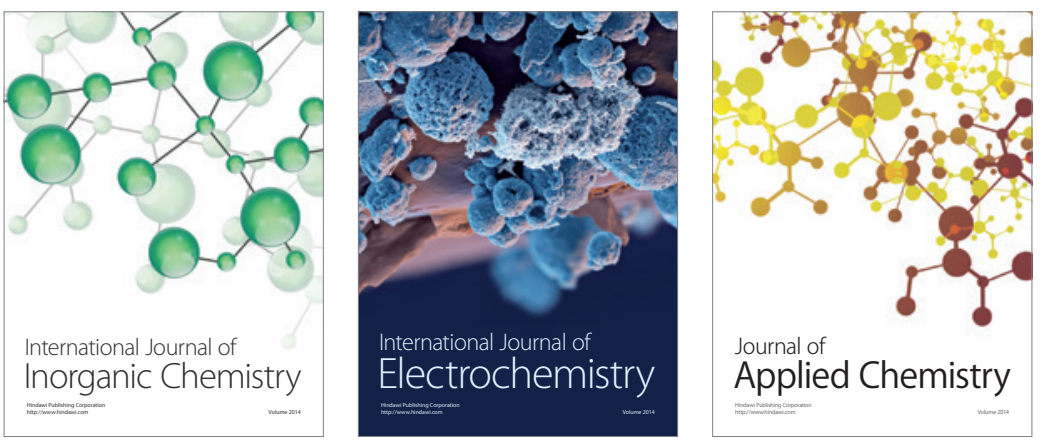

Journal of

Applied Chemistry
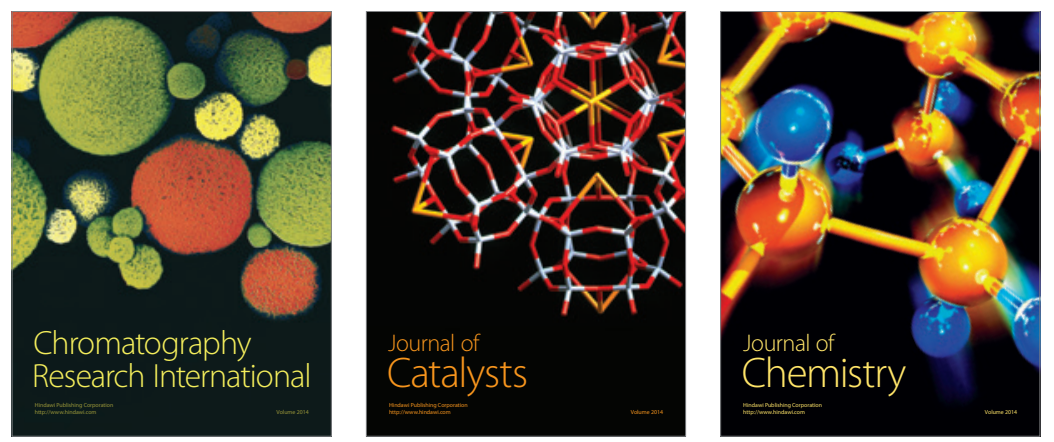
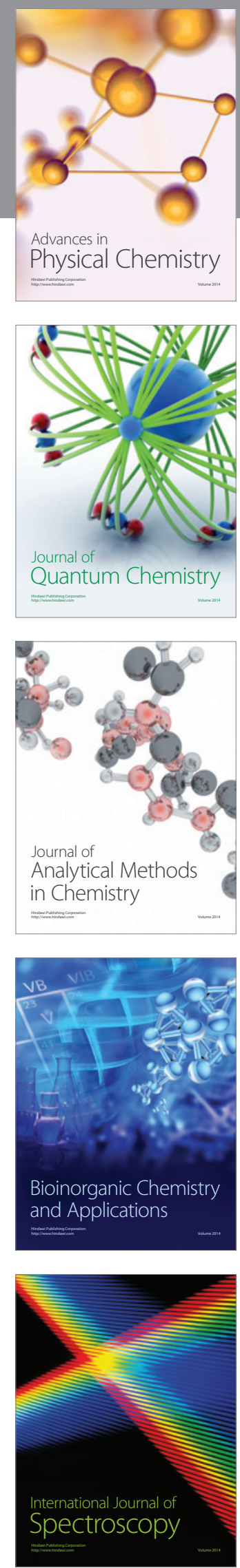